(6)

\section{OPEN ACCESS}

- Additional material is published online only. To view please visit the journal online (http://dx.doi.org/10.1136/ bjsports-2014-094469).

${ }^{1}$ FIFA Medical Assessment and Research Centre (F-MARC), Zürich, Switzerland

${ }^{2}$ Schulthess Klinik, Zürich, Switzerland

${ }^{3}$ Medical School Hamburg (MSH), Hamburg, Germany ${ }^{4}$ Fédération Internationale de Football Association (FIFA), Zürich, Switzerland

\section{Correspondence to}

Professor Dr Jiri Dvořák, Schulthess Klinik, F-MARC, Lengghalde 2, Zürich $\mathrm{CH}-8008$, Switzerland; Medical@FIFA.org

Accepted 25 February 2015

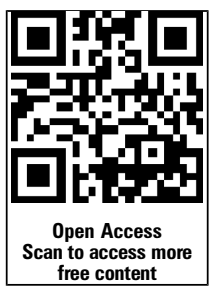

\title{
Football injuries during the 2014 FIFA World Cup
}

\author{
Astrid Junge, ${ }^{1,2,3}$ Jiri Dvořák ${ }^{1,2,4}$
}

\section{ABSTRACT \\ Background FIFA has surveyed match injuries in its tournaments since 1998.}

Aim To analyse the incidence and characteristics of match injuries incurred during the 2014 FIFA World Cup in comparison to previous FIFA World Cups.

Methods The chief physicians of the participating teams reported all newly incurred injuries of their players after the match on a standardised report form.

124 (97\%) forms were returned.

Results A total of 104 injuries were reported, equivalent to an incidence of 1.68 injuries per match (95\% Cl 1.36 to 2.00). 64 (63.4\%) injuries were caused by contact with another player. Thigh $(26 ; 25 \%)$ and head $(19 ; 18 \%)$ were the most frequently injured body parts. The most frequent diagnosis was thigh strain $(n=18)$. Five concussions and three fractures to the head were reported. While most thigh strains $(15 / 17 ; 88.2 \%)$ occurred without contact, almost all head injuries (18/19; 94.7\%) were caused by contact. 0.97 injuries per match $(95 \% \mathrm{Cl} 0.72$ to 1.22$)$ were expected to result in absence from training or match. Eight injuries were classified as severe. The incidence of match injuries in the 2014 FIFA World Cup was significantly lower than the average of the four preceding FIFA World Cups, both for all injuries $(2.34 ; 95 \% \mathrm{Cl} 2.15$ to 2.53$)$ and timeloss injuries $(1.51 ; 95 \% \mathrm{Cl} 1.37$ to 1.65$)$.

Conclusions The overall incidence of injury during the FIFA World Cups decreased from 2002 to 2014 by 37\%. A detailed analysis of the injury mechanism is recommended to further improve prevention strategies.

\section{INTRODUCTION}

The FIFA World Cup, one of the most popular sporting events, is watched on television by millions of people who, in turn, try to mimic the performance of football stars. This has an impact on playing football as a leisure activity for footballers of both genders and different age groups around the globe. The main objective of injury surveillance is to reduce the injury rate by analysing the types and mechanism of injuries in order to design and implement preventive measures.

Starting with the 1998 FIFA World Cup, FIFA has surveyed match injuries at all subsequent FIFA tournaments and football competitions of the Olympic Games. ${ }^{1} 2$ This database now enables comparison between competitions for different age, gender and skill levels and over time. ${ }^{2}$ The aim of the present study was to analyse the change in incidence and characteristics of injuries of football players participating in the five FIFA World Cups from 1998 to 2014.

\section{METHODS}

The injury definition and data collection procedure were in accordance with the respective consensus statement for football injuries, ${ }^{3}$ and have been described before in detail. ${ }^{12}$ An injury was defined as "any musculoskeletal complaint (including concussion) incurred during a match that received medical attention from the team physician regardless of the consequences with respect to absence from the match or training." ${ }^{2}$ As in previous FIFA World Cups, chief physicians of the 32 finalist teams were asked to report all injuries after each match on a specially designed injury report form. The injury report form was identical to the form used in $2002^{4}$ and $2006^{5}$ but slightly different to the one used in $2010^{6}$ (which in addition included training injuries and illnesses) and in $1998^{1}$ (which did not include information on time loss). Results of the FIFA World Cup 1998, ${ }^{1} 2002,{ }^{4} 2006^{5}$ and $2010^{6}$ have been published previously. ${ }^{2}$

The 64 matches of the 2014 FIFA World Cup were played from 12 June to 13 July 2014 at 12 different venues of Brazil. At each of the five FIFA World Cups, the participating 32 finalist teams (each with 23 players) comprised a total of 736 players. The number of matches per team varied between 3 and 7 .

Response rate, exposure time and incidences were calculated in accordance with the consensus statement and previous studies. ${ }^{1-6}$ Match exposure was calculated by multiplying $1.5 \mathrm{~h}$ by 11 players and by the number of returned forms. For incidence rates, 95\% CIs were calculated as the incidence \pm 1.96 times the incidence divided by the square root of the number of injuries. Data were processed using Excel (Microsoft 2008, V.12.3.6) and SPSS (PASW Statistics, V.18.0.3). Statistical methods applied were frequencies, cross-tabulations and $\chi^{2}$ test. Significance was accepted at the $5 \%$ level.

\section{RESULTS}

A total of 104 injuries were reported, which is equivalent to an average of 1.68 injuries per match (95\% CI 1.36 to 2.00 ) or 50.8 injuries per 1000 player hours (95\% CI 40.0 to 60.6$)$. The response rate was $97 \%$ (table 1 ).

Almost two-thirds of the injuries (64.4\%) were caused by contact, and more than a third $(34.9 \%$, $22 / 63$ ) of contact injuries-or $22.2 \%$ of all injuries -were caused by foul play based on the judgement of the team physician (table 2).

The injuries most frequently affected the lower extremity $(68 ; 65.4 \%)$ followed by the head/neck $(19 ; 18.3 \%)$, upper extremity $(10 ; 9.6 \%)$ and the trunk $(7 ; 6.7 \%)$. The most frequent diagnosis was a thigh strain $(n=18)$, and all thigh strains were expected to result in time loss. Nine thigh strains were incurred during the first half, five in the second half and one during extra time. Most (15/ $17 ; 88.2 \%)$ thigh strains were incurred without 
Table 1 Number of matches, response rate, severity and incidence of injury in FIFA World Cups

\begin{tabular}{|c|c|c|c|c|c|}
\hline Tournament & France 1998 & Korea/Japan 2002 & Germany 2006 & South Africa 2010 & Brazil 2014 \\
\hline Matches (n) & 64 & 64 & 64 & 64 & 64 \\
\hline Response rate & $124 / 128(97 \%)$ & $128 / 128(100 \%)$ & $128 / 128(100 \%)$ & $124 / 128(97 \%)$ & $124 / 128(97 \%)$ \\
\hline Match hours documented & 2046 & 2112 & 2112 & 2046 & 2046 \\
\hline Injuries (n) & 149 & 171 & 145 & 125 & 104 \\
\hline Injuries per 1000 player hours $(95 \% \mathrm{CI})$ & $72.8(61.1$ to 84.5$)$ & $81.0(68.9$ to 93.1$)$ & 68.7 (57.5 to 79.9$)$ & 61.1 (50.4 to 71.8$)$ & $50.8(41.0$ to 60.6$)$ \\
\hline Injuries per match $(95 \% \mathrm{Cl})$ & 2.40 (2.01 to 2.79$)$ & 2.67 (2.27 to 3.07$)$ & 2.27 (1.90 to 2.64$)$ & 2.02 (1.67 to 2.37$)$ & $1.68(1.36$ to 2.00$)$ \\
\hline \multicolumn{6}{|c|}{ Estimated duration of absence from sport (days) } \\
\hline 0 & & $53(33 \%)$ & $39(30 \%)$ & $39(35 \%)$ & $41(43 \%)$ \\
\hline $1-3$ & & $59(37 \%)$ & $43(33 \%)$ & $59(49 \%)$ & $15(16 \%)$ \\
\hline $4-7$ & & $27(17 \%)$ & $19(15 \%)$ & $9(7 \%)$ & $15(16 \%)$ \\
\hline $8-28$ & & $18(11 \%)$ & $23(18)$ & $3(3 \%)$ & $16(17 \%)$ \\
\hline 29 and more & & $3(2 \%)$ & $7(5 \%)$ & $2(2 \%)$ & $8(8 \%)$ \\
\hline Not specified & & 0 & 5 & 9 & 6 \\
\hline Missing & & 11 & 9 & 4 & 3 \\
\hline Injuries with subsequent absence & & 107 & 97 & 82 & 60 \\
\hline Injuries per $1000 \mathrm{~h}(95 \% \mathrm{Cl})$ & & 50.7 (41.1 to 60.3$)$ & 45.9 (36.8 to 55.0$)$ & 40.1 (31.4 to 48.8 ) & $29.3(21.9$ to 36.7$)$ \\
\hline Injuries per match $(95 \% \mathrm{CI})$ & & 1.67 (1.35 to 1.99$)$ & 1.51 (1.20 to 1.80$)$ & 1.29 (1.01 to 1.57$)$ & $0.97(0.72$ to 1.22$)$ \\
\hline
\end{tabular}

contact. Injuries to the head were diagnosed as laceration $(n=6)$, concussion $(n=5)$, contusion $(n=4)$, fracture $(n=3)$ or pain $(n=1)$. Almost all head injuries were caused by contact $(18 / 19$; 94.7\%); five were classified as foul play. Time loss in sport was not expected in 12 head injuries (including 3 concussions); however, one head injury (fracture and contusion) was classified as severe.

Approximately one injury per match was expected to result in absence from training or match (table 1). For eight injuries, the estimated duration of absence was more than 4 weeks: four

Table 2 Location, type and mechanism of injury in FIFA World Cups

\begin{tabular}{|c|c|c|c|c|c|}
\hline Tournament & France 1998 & Korea/Japan 2002 & Germany 2006 & South Africa 2010 & Brazil 2014 \\
\hline \multicolumn{6}{|l|}{ Injured body part } \\
\hline Head, face, neck & $16(15 \%)$ & $25(15 \%)$ & $13(9 \%)$ & $13(10 \%)$ & $19(18 \%)$ \\
\hline Upper extremity, including shoulder & $9(9 \%)$ & $8(5 \%)$ & $12(8 \%)$ & $12(10 \%)$ & $10(10 \%)$ \\
\hline Trunk & $9(9 \%)$ & $6(4 \%)$ & $15(10 \%)$ & $8(6 \%)$ & $7(7 \%)$ \\
\hline Hip/groin & $2(2 \%)$ & $11(6 \%)$ & $7(5 \%)$ & $6(5 \%)$ & $4(4 \%)$ \\
\hline Thigh & $21(20 \%)$ & $30(18 \%)$ & $21(14 \%)$ & $36(29 \%)$ & $26(25 \%)$ \\
\hline Knee & $24(23 \%)$ & $22(13 \%)$ & $17(12 \%)$ & $9(7 \%)$ & $12(12 \%)$ \\
\hline Lower leg & $6(6 \%)$ & $29(17 \%)$ & $30(21 \%)$ & $19(15 \%)$ & $13(12 \%)$ \\
\hline Ankle & $13(13 \%)$ & $25(15 \%)$ & $24(17 \%)$ & $15(12 \%)$ & $10(10 \%)$ \\
\hline Foot & $5(5 \%)$ & $14(8 \%)$ & $6(4 \%)$ & $7(6 \%)$ & $2(2 \%)$ \\
\hline Total & 105 & 170 & $145^{*}$ & 125 & 104 \\
\hline Missing/unclear & 44 & 1 & 0 & 0 & 0 \\
\hline \multicolumn{6}{|l|}{ Type of injury } \\
\hline Concussion & $1(1 \%)$ & $4(2 \%)$ & $1(1 \%)$ & $1(1 \%)$ & $5(5 \%)$ \\
\hline Fracture & $3(4 \%)$ & $3(2 \%)$ & $1(1 \%)$ & $4(3 \%)$ & $6(6 \%)$ \\
\hline Tendon or ligament rupture/meniscus lesion & $2(2 \%)$ & $1(1 \%)$ & $5(3 \%)$ & $1(1 \%)$ & $4(4 \%)$ \\
\hline Sprain (dislocation) & $10(12 \%)$ & $24(14 \%)$ & $24(15 \%)$ & $15(12 \%)$ & $8(8 \%)$ \\
\hline Strain/muscle fibre rupture & $19(23 \%)$ & $35(21 \%)$ & $20(14 \%)$ & $21(17 \%)$ & $25(24 \%)$ \\
\hline Contusion & $34(41 \%)$ & $84(50 \%)$ & $74(51 \%)$ & $53(43 \%)$ & $39(38 \%)$ \\
\hline Laceration/abrasion/blister & $6(7 \%)$ & $12(7 \%)$ & $6(4 \%)$ & $9(7 \%)$ & $10(10 \%)$ \\
\hline Others & $8(10 \%)$ & $6(2 \%)$ & $14(10 \%)$ & $20(16 \%)$ & $6(6 \%)$ \\
\hline Total & 83 & 169 & 145 & 124 & 103 \\
\hline Missing & 66 & 2 & 0 & 1 & 1 \\
\hline \multicolumn{6}{|l|}{ Mechanism of injury } \\
\hline Non-contact injuries & & 45/167 (27\%) & $38 / 142(27 \%)$ & $42 / 121(35 \%) \dagger$ & $36 / 101(36 \%)$ \\
\hline Contact injuries & & $122 / 167(73 \%)$ & $104 / 142(73 \%)$ & $79 / 121(65 \%) \dagger$ & $65 / 101(64 \%)$ \\
\hline Contact injury caused by foul & & $59 / 115(51 \%)$ & $57 / 93(61 \%)$ & $19 / 79(24 \%) \dagger$ & $22 / 63(35 \%)$ \\
\hline Foul sanctioned by the referee & & $28 / 54(52 \%)$ & $32 / 56(57 \%)$ & $-\dagger$ & $12 / 21(57 \%)$ \\
\hline
\end{tabular}

*One injury affected two body parts.

tMechanism of injury was assessed with a different question. ${ }^{6}$ 
fractures (arm, head, lumbar spine, lower leg), three knee injuries (ligament rupture, sprains, meniscus lesion) and a thigh strain. For six injuries, time loss was expected but the duration was not specified (a potential meniscus lesion, a concussion, headache due to a contact injury, two knee sprains and a contusion of the thigh).

The incidence of all injuries and of time-loss injuries declined from 2002 to 2014. The incidences of individual FIFA World Cups were not significantly different from each other, but the average incidence of the four previous FIFA World Cups was significantly higher both for all injuries $(2.34$; 95\% CI 2.15 to $2.53)$ and time-loss injuries $(1.51 ; 95 \%$ CI 1.37 to 1.65$)$ per match than the incidences during the 2014 FIFA World Cup. While the rate of non-contact injuries did not change significantly from 2002 (0.70 per match; 95\% CI 0.50 to 0.90$)$ to 2014 (0.60 per match; $95 \%$ CI 0.41 to 0.79 ), the average rate of contact injuries dropped constantly and significantly from 1.91 per match $(95 \%$ CI 1.57 to 2.25$)$ in 2002 to 1.03 per match (95\% CI 0.78 to 1.28 ) in 2014. The rate of injuries caused by foul play based on the judgement of the team physician also decreased significantly from 2002 (0.92 per match; $95 \%$ CI 0.69 to 1.15 ) to 2014 (0.35 per match; 95\% CI 0.20 to 0.50 ; figure 1$)$.

\section{DISCUSSION}

From a medical perspective, the objective is to prevent injuries by all possible means, ${ }^{7}$ beginning with the preparation for highlevel competition, ${ }^{8-10}$ surveillance of medical incidents during tournaments, ${ }^{1-6}$ and analysis of the injury mechanism after the event. ${ }^{11-15}$ Scientific evidence had even had an impact on the interpretation of the laws of the game: since 1998, tackling from behind should be sanctioned by a red card, and since 2006, elbow to head tackles should also be sanctioned by a red card. ${ }^{7}$ Both incidents have the potential of leading to severe injuries, and have now almost disappeared from the football game. 5611121415

Since 1998, the FIFA Medical Assessment and Research Centre (F-MARC) routinely performs injury surveillance at all FIFA competitions and football competitions of the Olympic Games. ${ }^{1}{ }^{2}$ The methodology applied is well established, and served as the basis for the injury surveillance systems of other sports federations and the IOC. ${ }^{16-21}$ Its limitations and

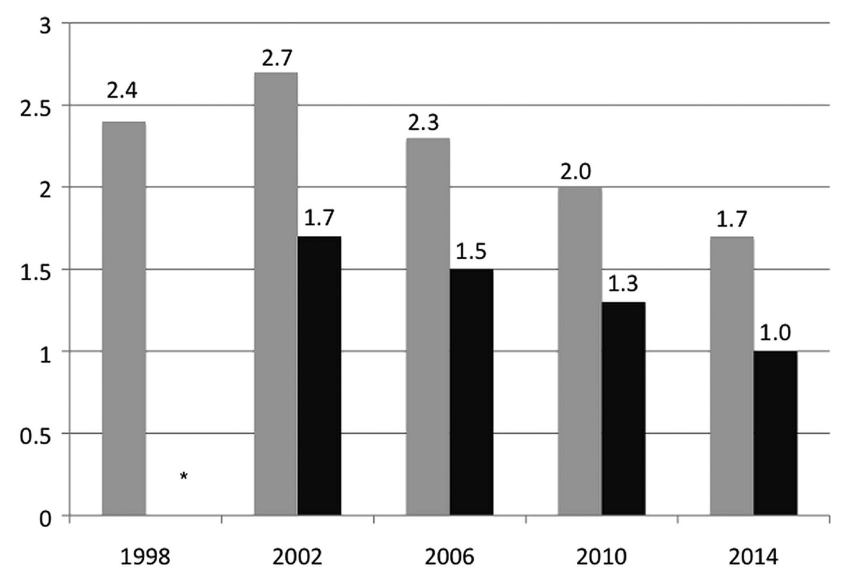

Figure 1 Number of injuries per match in FIFA World Cups 19982014 (all injuries (grey bars); injuries expected to result in time loss (black bars)); *information with regard to time loss was not documented during the 1998 FIFA World Cup. recommendations for improvements are outlined at the end of the discussion.

The injury incidences in FIFA World Cups constantly decreased from a peak of 2.67 injuries per match in 2002 to 1.68 injuries per match in 2014, equivalent to an overall decrease of $37 \%$. The proportion of contact injuries caused by foul play during the 2014 FIFA World Cup was substantially lower than in 2002 and 2006. This might not only be the result of strict refereeing but also the improved approach of the players towards fair play.

Collaboration between the FIFA Medical Officers and referees is developing progressively. Prior to the 2014 FIFA World Cup Brazil, all 90 referees were instructed on the medical aspects of the game for the first time by the FIFA Chief Medical Officer (JD), and urged to sanction accordingly for any contact incidences, which could potentially lead to injuries.

Although not statistically significantly increased, the number of head injuries and especially of concussions in the recent FIFA World Cup caused a lot of discussion. A video analysis of the five concussions showed that two were the result of head to head contact and one each of knee to head, head to ground and shoulder to head contact. These incidents were discussed among the FIFA medical experts, in particular with regard to the immediate management of concussion on the pitch. In consequence, the FIFA Executive Committee has approved the following proposal for the on-pitch assessment of players with a suspected concussion.

- "Whenever a suspected incident of concussion occurs, the referee will have the ability to stop the game for three minutes, allowing the relevant team doctor to complete an on-pitch assessment and decide if the player has suspected concussion.

- The referee will only allow the injured party to continue playing with the authorisation of the team doctor, who will have the final decision." 22

Although concussions are rare in football (a total of 12 concussions were reported during the last five FIFA World Cups), it is important to educate the team physicians on the appropriate management, in particular the immediate and permanent removal of the player from the pitch after obvious or even suspected concussion. $^{23}$

Almost two-thirds of the injuries during the 2014 FIFA World Cup affected the lower extremity, with thigh strain being the most frequent diagnosis. This result is in accordance with previous studies on football injuries of professional male players, especially if time-loss injuries were analysed. ${ }^{4}{ }^{24-27}$ Since thigh strains are mostly incurred without contact, it is recommended to include preventive exercises in the teams' training routine. Cochrane reviews on the prevention of these injuries concluded that there is insufficient evidence on the effectiveness of interventions used to prevent hamstring injuries in football players, ${ }^{28}$ and very weak evidence for the effectiveness of interventions to reduce lower limb soft-tissue injury after intensive running. ${ }^{29}$ However, three recently published intervention studies showed that eccentric strength training reduced the risk of hamstring strains in male football players. ${ }^{30-32}$

\section{Limitations and recommendations to improve the methodology}

This study focused on acute match injuries; thus, chronic injuries, training injuries and illness/diseases were not registered. As shown in our study during the 2010 FIFA World Cup, ${ }^{6}$ training injuries were almost as frequent as match injuries, and illnesses 
affected about $12 \%$ of the players. It should be considered to expand the medical reports to training injuries and illnesses, to cover all impairments of players' health during the tournament, as in the medical surveillance systems of IOC, ${ }^{33}{ }^{34}$ IAAF (International Association of Athletics Federations) ${ }^{35}$ and FINA (Fédération Internationale de Natation) ${ }^{20}$

Exposure time was calculated based on 22 players and a 90 min match for all FIFA World Cups. ${ }^{1}{ }^{2}$ A more precise method would be to regard extra time or the actual playing time of each match.

Although the response rate in the 2014 and the previous FIFA World Cups was high (97-100\%), ${ }^{1}$ the number of missing values should be further reduced, especially for estimated duration of time loss from sport. A follow-up of injured players until their return to full training and match play would improve the accuracy of this information and also provide the opportunity to specify or revise the diagnosis, which might not always be exact when reported immediately after the match. To the best of our knowledge, only the International Rugby Board Surveillance Study follows up injured players after their championships. $^{36} 37$

The FIFA injury surveillance system relies exclusively on information provided by the team physicians, and it cannot be excluded that some injuries were not reported or details were wrongly recorded. Video analysis seems to be the most objective measure to assess occurrence of injury, its mechanism and the related action of the referee. However, a comparison of the physicians' injury reports and video footage performed during the 2006 FIFA World Cup showed that not all injuries reported by the team physicians could be found in the video footage, and not all on-pitch treatments seen in the video recording of the matches were reported as injuries by the team physicians. ${ }^{5}$ Nevertheless, video analysis is an important tool to study the injury mechanism and an objective source for a referee's decision, and thus should be used to complement the team physicians' injury reports.

\section{CONCLUSION}

The overall injury rate decreased from the 2002 to the 2014 FIFA World Cup by $37 \%$. While the incidence of non-contact injuries did not change significantly, a significant reduction in the rate of contact injuries and of injuries caused by foul play was observed from the 2002 to the 2014 FIFA World Cup. This may not only be a result of strict refereeing but also the improved approach of the players towards fair play. Thigh and head were the most frequently injured body parts in the 2014 FIFA World Cup. Interventions to prevent non-contact injuries of the lower extremity should be part of the training routine. Team physicians have to be informed on the appropriate management of (suspected) concussion, in particular the immediate and permanent removal of the player from the pitch.

\section{What are the new findings?}

- The overall incidence of injury during FIFA World Cups constantly decreased from 2002 to 2014.

- While the incidence of non-contact injuries did not change significantly, a significant reduction in the rate of contact injuries and of injuries caused by foul play was observed from the 2002 to the 2014 FIFA World Cup.
How might it impact on clinical practice in the near future?

- More attention should be paid to the management of concussion on the pitch.

- Interventions to prevent non-contact injuries should be part of the training routine.

- The injury surveillance system should include a follow-up of injured players to specify the diagnosis and the exact duration of absence from sport. Video footage should be analysed with regard to injury mechanism and referee's sanction.

Acknowledgements The authors appreciate the cooperation of all team physicians who gave their time to collect the data for this project. They also express their gratitude to the FIFA Medical Officers (Professor Hosny A. Ahmed, Dr Terence Babwah, Dr Jiri Chomiak, Dr Tony Edwards, Dr Ecki Hermann, Professor Efraim Kramer, Dr Raul Madero, Dr Bert Mandelbaum, Dr Fredy Muller, Dr Carlos Palavicini, Professor Lars Peterson, Dr Gurcharan Singh, Dr Martin Vaso) and the FIFA administrative staff (Anja König, Philipp Tobler).

Funding This study was funded by FIFA.

Competing interests None.

\section{Patient consent Obtained.}

Ethics approval Ethics commission University of Zurich.

Provenance and peer review Not commissioned; externally peer reviewed.

Open Access This is an Open Access article distributed in accordance with the Creative Commons Attribution Non Commercial (CC BY-NC 4.0) license, which permits others to distribute, remix, adapt, build upon this work non-commercially, and license their derivative works on different terms, provided the original work is properly cited and the use is non-commercial. See: http://creativecommons.org/ licenses/by-nc/4.0/

\section{REFERENCES}

1 Junge A, Dvořák J, Graf-Baumann T, et al. Football injuries during FIFA tournaments and the Olympic Games, 1998-2001: development and implementation of an injury-reporting system. Am J Sports Med 2004;32(1 Suppl): 80S-9S.

2 Junge A, Dvořák J. Injury surveillance in world football tournaments 1998-2012. Br J Sports Med 2013;47:782-8.

3 Fuller CW, Ekstrand J, Junge $A$, et al. Consensus statement on injury definitions and data collection procedures in studies of football (soccer) injuries. Br J Sports Med 2006;40:193-201.

4 Junge A, Dvořák J, Graf-Baumann T. Football injuries during the World Cup 2002. Am J Sports Med 2004;32(1 Suppl):23S-7S.

5 Dvořák J, Junge A, Grimm K, et al. Medical report from the 2006 FIFA World Cup Germany. Br J Sports Med 2007;41:578-81.

6 Dvořák J, Junge A, Derman W, et al. Injuries and illnesses of football players during the 2010 FIFA World Cup. Br J Sports Med 2011;45:626-30.

7 Fuller $C W$, Junge $A$, Dvořák J. Risk management: FIFA's approach for protecting the health of football players. Br J Sports Med 2012;46:11-17.

8 Dvořák J, Grimm K, Schmied C, et al. Development and implementation of a standardized precompetition medical assessment of international elite football players_-2006 FIFA World Cup Germany. Clin J Sport Med 2009;19:316-21.

9 Dvořák J, Grimm K, Schmied C, et al. Feasibility of Pre-Competition Medical Assessment (PCMA) at FIFA World Cups for female youth players. Br I Sports Med 2012;46:1132-3.

10 Dvořák J, Kramer EB, Schmied CM, et al. The FIFA medical emergency bag and FIFA 11 steps to prevent sudden cardiac death: setting a standard and promoting consistent football field emergency care. Br J Sports Med 2013;47:1199-202.

11 Fuller CW, Smith GL, Junge A, et al. An assessment of player error as an injury causation factor in international football. Am J Sports Med 2004;32(1 Suppl):28S-35S.

12 Fuller $\mathrm{CW}$, Smith $\mathrm{GL}$, Junge $\mathrm{A}$, et al. The influence of tackle parameters on the propensity for injury in international football. Am J Sports Med 2004;32(1 Suppl):43S-53S.

13 Fuller CW, Junge A, Dvořák J. A six year prospective study of the incidence and causes of head and neck injuries in international football. Br J Sports Med 2005;39 (1 Suppl):i3-9. 
14 Tscholl P, O'Riordan D, Fuller CW, et al. Causation of injuries in female football players in top-level tournaments. Br J Sports Med 2007;41(1 Suppl):i8-14.

15 Tscholl P, O'Riordan D, Fuller CW, et al. Tackle mechanisms and match characteristics in women's elite football tournaments. Br I Sports Med 2007; 41(1 Suppl):i15-19.

16 Langevoort G, Myklebust G, Dvořák J, et al. Handball injuries during major international tournaments. Scand J Med Sci Sports 2007;17:400-7.

17 Junge A, Engebretsen L, Alonso JM, et al. Injury surveillance in multi-sport eventsthe International Olympic Committee approach. Br I Sports Med 2008;42:413-21.

18 Junge $A$, Engebretsen L, Mountjoy M, et al. Sports injuries during the Summer Olympic Games 2008. Am J Sports Med 2009;37:2165-72.

19 Alonso JM, Junge $A$, Renström $P$, et al. Sports injury surveillance during the 2007 IAAF World Athletics Championships. Clin I Sports Med 2009:19:26-32.

20 Mountjoy M, Junge A, Alonso JM, et al. Sports injuries and illnesses in the 2009 FINA World Championships (Aquatics). Br I Sports Med 2010;44:522-7.

21 Feddermann $\mathrm{N}$, Junge $\mathrm{A}$, Edouard $\mathrm{P}$, et al. Injuries in 13 international athletics championships 2007-2012. Br J Sport Med Med 2014:48:513-22.

22 http://www.fifa.com/aboutfifa/footballdevelopment/medical/news/newsid=2443024/ (accessed 25 Nov 2014).

23 McCrory P, Meeuwisse WH, Aubry M, et al. Consensus Statement on Concussion in Sport: the 4th International Conference on Concussion in Sport Held in Zurich, November 2012. Br J Sports Med 2013;47:250-8.

24 Walden $M$, Hagglund $M$, Ekstrand J. Football injuries during European Championships 2004-2005. Knee Surg Sports Traumatol Arthrosc 2007:15:1155-62.

25 Ekstrand J, Hägglund M, Waldén M. Injury incidence and injury patterns in professional football: the UEFA injury study. Br I Sports Med 2011;45:553-8.
26 Waldén $\mathrm{M}$, Hägglund $\mathrm{M}$, Ekstrand J. Injuries in Swedish elite football—a prospective study on injury definitions, risk for injury and injury pattern during 2001. Scand I Med Sci Sports 2005;15:118-25.

27 Eirale C, Faroog A, Smiley FA, et al. Epidemiology of football injuries in Asia: a prospective study in Qatar. J Sci Med Sport 2013;16:113-17.

28 Goldman EF, Jones DE. Interventions for preventing hamstring injuries. Cochrane Database Syst Rev 2010;(1):CD006782.

29 Yeung SS, Yeung EW, Gillespie LD. Interventions for preventing lower limb soft-tissue running injuries. Cochrane Database Syst Rev 2011;(7):CD001256.

30 Arnason A, Andersen TE, Holme I, et al. Prevention of hamstring strains in elite soccer: an intervention study. Scand I Med Sci Sports 2008;18:40-8.

31 Petersen J, Thorborg K, Nielsen MB, et al. Preventive effect of eccentric training on acute hamstring injuries in men's soccer: a cluster-randomized controlled trial. Am J Sports Med 2011;39:2296-303.

32 Nichols AW. Does eccentric training of hamstring muscles reduce acute injuries in soccer? Clin I Sport Med 2013;23:85-6.

33 Engebretsen L, Steffen K, Alonso JM, et al. Sports injuries and illnesses during the Winter Olympic Games 2010. Br J Sports Med 2010;44:772-80.

34 Engebretsen L, Soligard T, Steffen K, et al. Sports injuries and illnesses during the London Summer Olympic Games 2012. Br J Sports Med 2013;47:407-14.

35 Timpka T, Alonso JM, Jacobsson J, et al. Injury and illness definitions and data collection procedures for use in epidemiological studies in athletics (track and field): consensus statement. Br J Sports Med 2014;48:483-90.

36 Fuller CW, Laborde F, Leather RJ, et al. International Rugby Board Rugby World Cup 2007 injury surveillance study. Br I Sports Med 2008;42:452-9.

37 Fuller CW, Sheerin K, Targett S. Rugby World Cup 2011: International Rugby Board injury surveillance study. Br I Sports Med 2013;47:1184-91. 